\title{
Perbandingan Perencanaan Tebal Perkerasan Kaku dengan Menggunakan Metode Bina Marga 04/Se/Db/2017 dan Metode Aashto 1993
}

\author{
Comparison of Rigid Pavement Thickness Planning Using the Bina Marga Method 04 / Se / Db / \\ 2017 and the Aashto 1993 Method
}

\author{
Almufid, Saiful Haq, Silwanus \\ Program Studi Teknik Sipil \\ Fakultas Teknik - Universitas Muhammadiyah Tangerang \\ J1. Perintis Kemerdekaan 1 / 33 , Cikokol Tangerang \\ Email Koresponden : almufid st@yahoo.com, saiful haq@yahoo.com, silwanbll@gmail.com
}

\begin{abstract}
ABSTRAK
Jalan merupakan salah satu prasarana perhubungan darat yang mempunyai peranan penting bagi kehidupan manusia. Selain perencanaan geometrik jalan, perkerasan jalan merupakan bagian dari perencanaan jalan yang harus direncanakan secara efektif dan efisien, karena kebutuhan tingkat pelayanan jalan semakin tinggi. Jalan Perjuangan merupakan salah satu bagian jalan di Jakarta barat yang jalannya sudah digunakan. Pekerjaan jalan ini menggunakan perkerasan kaku, agar perkerasan tahan sampai pada masa layannya, maka perlu metode desain yang tepat dalam perencanaannya. Terdapat banyak metode untuk mendesain tebal pelat beton ini, diantaranya metode Bina Marga 2017 dan AASHTO 1993. Tugas Akhir ini bertujuan untuk menganalisis alternatif desain tebal perkerasan mengkaji pada parameter perencanaan kedua metode, perencanaan tebal pelat beton, dan melakukan analisa perbandingan hasil kedua metode. Metode ini dimulai dengan pengumpulan data primer berupa data lalu lintas dan data tanah. Setelah itu pengumpulan data sekunder yang berupa data pertumbuhan lalu lintas dan data hidrologi, kemudian dilakukan perhitungan tebal pekerasan dengan menggunakan kedua metode, dan hasil perhitungannya lalu dilakukan perbandingan antara kedua metode tersebut. Dalam perencanaan perhitungan tebal pelat dibutuhkan parameter input untuk masingmasing metode. Parameter input perencanaan tebal perkerasan untuk metode Bina Marga 2017 adalah parameter lalu lintas, tanah dasar, pondasi bawah, pondasi bawah material berbutir, dan kekuatan beton. Parameter input perencanaan tebal perkerasan untuk metode AASHTO 1993 adalah parameter lalu lintas, modulus reaksi tanah dasar, material konstruksi perkerasan, realibility, dan koefisien drainase. Untuk studi kasus yaitu pada jalan perjuangan grogol Jakarta barat, tebal pelat beton berdasarkan perhitungan metode Bina Marga 2017 adalah 28,5 cm, sedangkan berdasarkan metode AASHTO 1993 adalah $26 \mathrm{~cm}$. Selisih yang didapat cukup kecil yaitu 2,5 cm. Hal ini dikarenakan perbedaan parameter input dari masing-masing metode dan data lalu lintas kendaraan yang melintasi jalan tersebut yang cukup kecil.
\end{abstract}

Kata kunci : Tebal perkerasan kaku, Bina marga 2017, AASHTO 1993

\section{PENDAHULUAN}

Perkembangan Ilmu Pengetahuan dan Teknologi (IPTEK) yang sangat pesat, berdampak pula pada perkembangan dunia konstruksi yang beragam jenisnya. Konstruksi jalan yang dipakai pun berkembang pesat seiring perkembangan teknologi. Dari yang awalnya hanya memadatkan tanah saja sampai dengan pemakaian susunan perkerasan yang lebih lengkap dengan menggunakan beberapa lapisan.

Ada dua jenis perkerasan yang kita kenal, yaitu perkerasan lentur (Flexible 
Pavement) dan perkerasan kaku (Rigid Pavement). Secara struktural keduanya memiliki perbedaan. Perkerasan lentur terdiri dari lapisan yang mempunyai fungsi berbeda, sedangkan perkerasan kaku hanya terdiri dari satu lapisan atau single layer system yang berupa pelat beton. Di Indonesia perkerasan lentur sudah mulai ditinggalkan dan mulai menggunakan sistem perkerasan kaku.

Perkerasan kaku adalah perkerasan yang menggunakan semen sebagai bahan pengikatnya sehingga mempunyai modulus elastisitas yang rendah. Pada umumnya terdiri dari lapisan beton semen yang dipasang langsung atau perantaraan selapis tipis pondasi diatas tanah dasar. Tingginya kekakuan pada perkerasan menyebabkan penyebaran beban oleh perekarasan tanah dasar relatif lebih luas dan beban sebagian besar dipikul oleh perkerasan tersebut.

Pada perkerasan kaku, perawatan jalan pada masa pemakaian atau pelayanan jalan tersebut tidak terlalu mahal, dikarenakan perkerasan kaku lebih tahan terhadap proses keausan maupun pelapukan baik secara mekanis maupun kimiawi sehingga tidak memerlukan perawatan atau rehab jalan kembali dalam waktu yang panjang.

dalam penelitian ini mengambil lokasi studi di jalan Perjuangan kebon jeruk Jakarta barat Dengan perkembangan pertumbuhan lalu lintas di ibu kota jakarta yang setiap tahun bertambah, maka perlu diadakan peningkatan fungsi infrastruktur.

Adapun tujuan dalam penulisan Tugas Akhir ini adalah :

a. Menghitung tebal perkerasan kaku dengan menggunakan metode Bina marga 2017 dan AASHTO 1993

b. membandingkan hasil dari perencanaan perkerasan kaku dengan menggunakan metode bina marga 2017 dan AASHTO 1993

\section{Pengertian Jalan}

Definisi jalan adalah prasarana transportasi darat yang meliputi segala bagian jalan, termasuk bangunan pelengkap, dan perlengkapannya yang diperuntukkan bagi lalulintas, yang berada permukaan tanah, diatas permukaan tanah, dibawah permukaan tanah dan atau air, serta diatas permukaan air, kecuali jalan kereta api dan jalan kabel (UU No. 38 tahun 2004 tentang Jalan),( Manual Desain Perkerasan Jalan Kementerian PU Direktorat Jenderal Bina Marga (Nomor : 04/SE/Db/2017)

\section{Jenis - Jenis Jalan}

a) Jalan Raya merupakan suatu landasan yang bertujuan untuk melewatkan lalu lintas dari suatu tempat ke tempat yang lain. Untuk itu jalan raya harus dibuat dengan aman,cepat, tepat, nyaman,efisien dan ekonomis

b) Jalan Umum adalah jalan yang diperuntukkan bagi lalu lintas umum.

c) Jalan Khusus adalah jalan yang di bangun oleh instasi, badan usaha. Perseorangan, atau kelompok masyarakat untuk kepentingan sendiri.

d) Jalan Tol atau pengertian jalan bebas hambatan adalah jalan umum yang merupakan bagian sistem jaringan jalan dan sebagai jalan nasional yang penggunanya diwajibkan membayar tol. Tol adalah sejumlah uang tertentu yang dibayarkan untuk penggunaan jalan tol.

\section{Volume lalu lintas}

Volume lalu lintas menunjukkan jumlah kendaraan yang melintasi satu titik pengamatan dalam satu satuan waktu (hari,jam,menit). Volume lalu lintas dalam SMP ini menunjukkan besarnya jumlah Lalu lintas Harian Rata-rata (LHR) yang melintasi jalan tersebut. Dari Lalu Lintas Rata-rata (LHR) yang didapatkan kita dapat mengklasifikasi jalan tersebut seperti terlihat pada tabel di bawah ini : 


\begin{tabular}{|c|c|c|c|}
\hline No & Klasifikasi Jalan & Kelas & $\begin{array}{c}\text { Lalulintas Harian } \\
(\mathrm{smp})\end{array}$ \\
\hline 1 & Jalan utama & I & $>20.000$ \\
\hline \multirow{2}{*}{2} & & IIA & $6000-20.000$ \\
\cline { 3 - 4 } & \multirow{2}{*}{ Jalan sekunder } & IIB & $1.500-8.000$ \\
\cline { 3 - 4 } & & IIC & $<2.000$ \\
\hline 3 & Jalan penghubung & III & - \\
\hline
\end{tabular}

\section{METODE PENELITIAN}

Untuk pelaksanaan penelitian ini, peneliti menggunakan data primer yang didapat dari nilai DCP dan data jumlah kendaraan dari survey langsung dilapangan. Adapun tinjauan lokasi penelitian ini adalah J1. Perjuangan, Kebon jeruk Jakarta Barat, ada tahap - tahap dalam penelitian ini adalah :

1. Kegiatan pengumpulan data Primer, pada pelaksanaan pekerjaan rigid pavement ruas jalan Perjuangan kebon jeruk berupa data tanah dan data lalu-lintas.

2. perhitungan tebal rigid pavement pada ruas jalan Parit Haji Muksin II dengan menggunakan metode Bina Marga 20017 dan AASHTO 1993.

3. Membandingkan tebal perkerasan hasil perhitungan Bina Marga 20017 dan AASHTO 1993.

4. Menjelaskan hasil perhitungan tebal perkerasan dan pembahasan secara jelas dan singkat.

5. Menjelaskan kesimpulan dan saran yang didapat dari penelitian yang telah dilakukan.

\section{HASIL DAN PEMBAHASAN}

4.1 Perhitungan teba pelat beton dengan menggunakan metode bina marga 2017

1. CBR tanah dasar $=5 \%$

2. Kuat tekan beton : K $350=\mathrm{fc}: 29,05 \mathrm{Mpa}$

3. Bahan pondasi bawah : beton kurus $10 \mathrm{~cm}$

4. Mutu baja tulangan $=$ BJTU 24

5. Ruji dowel : ya

6. Data lalu lintas harian rata - rata :
a. Mobil penumpang
$=2919$ kendaraan
b. Bus
$=25$ kendaraan
c. Truk 2 as kecil $=90$ kendaraan

7. Umur rencana $=40$ tahun

8. Pertumbuhan lalu lintas (i) : 3,5 tahun

9. Menghitung nilai CESA 
JTS : Jurnal Teknik

\begin{tabular}{|c|c|c|c|c|c|c|c|}
\hline NO & $\begin{array}{c}\text { JENIS } \\
\text { KENDARAAN }\end{array}$ & LHRT & DL & VDF4 & ESA4 & $\mathbf{R}$ & CESA4 \\
\hline 1 & Mobil Penumpang & 2,858 & $80 \%$ & & & 84.55028 & - \\
\hline 2 & Bus & 52 & $80 \%$ & 0.3 & 12 & 84.55028 & 385,143 \\
\hline 3 & Truk 2 As Kecil & 87 & $80 \%$ & 0.3 & 21 & 84.55028 & 644,375 \\
\hline \multicolumn{5}{|c|}{ TOTAL } & 461 & & 1029518 \\
\hline
\end{tabular}

10. Pemilihan struktur pondasi jalan

Pemilihan struktur pondasi jalan didasarkan pada tabel penentuan pondasi.

Karena nilai CBR $=5 \%$ maka kelas kekuatan tanah dasar menggunakan SG5

(pemadatan lapisan $<200 \mathrm{~mm}$ tebal gembur)

11. Menentukan lapisan subbase dan tebal pelat beton

Berdasarkan bagan desain 4 didapat tebal perkerasan kaku adalah $285 \mathrm{~mm}$

Lapis pondasi $\mathrm{LMC}=100 \mathrm{~mm}$

Lapis pondasi agregat kelas $\mathrm{A}=150 \mathrm{~mm}$

\begin{tabular}{|c|c|c|c|c|c|}
\hline Struktur Perkerasan & $\begin{array}{l}\mathbf{R} \\
\mathbf{1}\end{array}$ & $\mathbf{R} 2$ & $\mathbf{R 3}$ & $\mathbf{R 4}$ & R5 \\
\hline $\begin{array}{l}\text { Kelompok sumbu } \\
\text { kendaraan berat } \\
\text { (overloaded) (10E6) }\end{array}$ & $\begin{array}{l}< \\
4 \\
3\end{array}$ & $<8.6$ & & $<43$ & $<86$ \\
\hline Dowel dan bahu beton & \multicolumn{5}{|c|}{\begin{tabular}{|l|l|}
$\mathrm{Y}$ \\
$\mathrm{a}$ \\
\end{tabular}} \\
\hline \multicolumn{6}{|c|}{ STRUKTUR PERKERASAN (mm) } \\
\hline Tebal pelat beton & $\begin{array}{l}2 \\
6 \\
5\end{array}$ & 275 & 285 & 95 & 305 \\
\hline \multicolumn{6}{|l|}{ Lapis Fondasi LMC } \\
\hline $\begin{array}{l}\text { Lapis Drainase } \\
\text { (dapat mengalir dengan } \\
\text { baik) }\end{array}$ & & & & & \\
\hline
\end{tabular}

12. Perhitungan tulangan
a. Tebal pelat (h)
b. Lebar pelat (L)
$=28,5 \mathrm{~cm}$ lajur)
c. Panjang pelat (P) (jarak antar sambungan)
$=7 \mathrm{~m}$ (untuk 2
d. Koefisien gesek antar pelat beton dengan
$=10 \mathrm{~m}$ pondasi bawah (F)
$=1,5$
$=240 \mathrm{MPa}$
e. Kuat tarik ijin baja
$=2400 \mathrm{~kg} / \mathrm{m} 3$
f. Berat isi beton
$=9,81 \mathrm{~m} / \mathrm{dt} 2$
g. Gravitasi (g) 
13. Tulangan memanjang

a. $\quad \mathrm{As}=\underline{F} \cdot P \cdot M \cdot g \cdot h$

$$
\text { As }=\frac{1,5 \times 10 \times 2400 \times 9,81 \times 0,285}{2 \times 240}
$$

As $=209,68 \mathrm{~mm}^{2} / \mathrm{m}$

b. As $\min =0,1 \% \times 285 \times 1000=285 \mathrm{~mm}^{2} / \mathrm{m}>$ As perlu

c. Untuk mencari diameter tulangan memanjang yang digunakan dapat menggunakan rumus berikut :

As $=1 / 4 \pi \mathrm{d} 2$

$$
\begin{aligned}
& 28,50=1 / 4 \times 3,14 \times \mathrm{d} 2 \\
& 28,50=0,785 \times \mathrm{d} 2 \\
& d=\sqrt{ } 28,50 \div 0,785 \\
& d=6,025 \sim \mathbf{6} \mathbf{~ m m}
\end{aligned}
$$

d. Kontrol

As $=1 / 4 \pi \mathrm{d} 2$

\begin{tabular}{|c|c|c|c|c|c|c|}
\hline \multicolumn{2}{|c|}{$\begin{array}{c}\text { Tulangan } \\
\text { Memanjang }\end{array}$} & \multicolumn{2}{|c|}{ Tulangan melintang } & \multicolumn{2}{|c|}{$\begin{array}{c}\text { Luas Penampang } \\
\text { Tulangan } \\
\end{array}$} & \multirow{2}{*}{$\begin{array}{c}\text { Berat per Satuan } \\
\text { Luas } \\
\left(\mathrm{kg} / \mathrm{m}^{2}\right)\end{array}$} \\
\hline $\begin{array}{c}\text { Diameter } \\
(\mathrm{mm})\end{array}$ & $\begin{array}{l}\text { Jarak } \\
(\mathrm{mm})\end{array}$ & $\begin{array}{c}\text { Diameter } \\
(\mathrm{mm})\end{array}$ & $\begin{array}{l}\text { Jarak } \\
(\mathrm{mm})\end{array}$ & $\begin{array}{l}\text { Memanjang } \\
\left(\mathrm{mm}^{2} / \mathrm{m}\right)\end{array}$ & $\begin{array}{l}\text { Melintang } \\
\left(\mathrm{mm}^{2} / \mathrm{m}\right)\end{array}$ & \\
\hline \multicolumn{7}{|c|}{ Empat persegi panjang } \\
\hline 12,5 & 100 & 8 & 200 & 1227 & 251 & 11,606 \\
\hline 11,2 & 100 & 8 & 200 & 986 & 251 & 9,707 \\
\hline 10 & 100 & 8 & 200 & 785 & 251 & 8,138 \\
\hline 9 & 100 & 8 & 200 & 636 & 251 & 6,967 \\
\hline 8 & 100 & 8 & 200 & 503 & 251 & 5,919 \\
\hline 7,1 & 100 & 8 & 200 & 396 & 251 & 5,091 \\
\hline 9 & 200 & & 250 & & 201 & 4,076 \\
\hline 8 & 200 & 8 & 250 & 25 & 201 & 3,552 \\
\hline \multicolumn{7}{|c|}{ Bujur sangkar } \\
\hline 8 & 100 & 8 & 100 & 503 & 503 & 7,892 \\
\hline 10 & 200 & 10 & 200 & 393 & 393 & 6,165 \\
\hline 9 & 200 & 9 & 200 & 318 & 318 & 4,994 \\
\hline 8 & 200 & 8 & 200 & 251 & 251 & 3,946 \\
\hline 7,1 & 200 & 7,1 & 200 & 198 & 198 & 3,108 \\
\hline 6,3 & 200 & 6,3 & 200 & 156 & 156 & 2,447 \\
\hline 5 & 200 & 5 & 200 & 98 & 98 & 1,542 \\
\hline 4 & 200 & 4 & 200 & 63 & 63 & 0,987 \\
\hline
\end{tabular}

As $=1 / 4 \times 3,14 \times 6^{2}$

As $=28,26 \times 10$

As $=282,6 \mathrm{~mm} 2 / \mathrm{m}>$ As perlu $=209,68 \mathrm{~mm} 2 / \mathrm{m}$

Dipergunakan tulangan diameter $6 \mathbf{~ m m}$, jarak $200 \mathbf{~ m m}$ (berdasarkan tabel ukuran dan berat tulangan polos anyaman las)

14. Tulangan Melintang

a. $\quad$ As $=\underline{F \cdot L \cdot M \cdot g \cdot h}$

$$
\text { 2. } f \mathrm{~s}
$$

As $=\underline{1,5 \times 7 \times 2400 \times 9,81 \times 0,285}$

$$
2 \times 240
$$

As $=146.7824 \mathrm{~mm}^{2} / \mathrm{m}$

b. As $\min =0,1 \% \times 285 \times 1000=285 \mathrm{~mm}^{2} / \mathrm{m}>$ As perlu

c. Untuk mencari diameter tulangan memanjang yang digunakan dapat menggunakan rumus berikut :

As $=1 / 4 \pi \mathrm{d} 2$

$28,50=1 / 4 \times 3,14 \times \mathrm{d} 2$

$28,50=0,785 \times \mathrm{d} 2$ 


$$
\mathrm{d}=6,025 \sim 6 \mathrm{~mm}
$$

d. Kontrol

$$
\begin{aligned}
& \text { As }=1 / 4 \pi \mathrm{d} 2 \\
& \text { As }=1 / 4 \times 3,14 \times 6^{2} \\
& \text { As }=28,26 \times 10 \\
& \text { As }=282,6 \mathrm{~mm} 2 / \mathrm{m}>\text { As perlu }=209,68 \mathrm{~mm} 2 / \mathrm{m}
\end{aligned}
$$

Dipergunakan tulangan diameter $6 \mathbf{m m}$, jarak $250 \mathrm{~mm}$ (berdasarkan tabel ukuran dan berat tulangan polos anyaman las)

1. Tebal perkerasan

$$
\begin{aligned}
\text { 1. Tebal perkerasan } & =28,5 \mathrm{~cm} \quad\left({ }^{*} 1 \text { in }=2,54 \mathrm{~cm}\right) \\
& =28,5 / 2,54 \\
& =11,2 \mathrm{in} \sim 12 \mathrm{in} \\
& =11,48 \sim 12 \mathrm{ft} \\
\text { 2. Jarak Maksimum Tie bar } & =26 \text { in }(\text { dari grafik } 4.4)\left({ }^{*} 1 \text { in }=2,54 \mathrm{~cm}\right) \\
& =26 \times 2,54 \\
& =66,04 \mathrm{~cm}=660,4 \mathrm{~mm} \sim \mathbf{6 5 0} \mathbf{~ m m} \\
\text { 3. Panjang Besi } & =25 \text { in }(\text { dari tabel } 3.21)\left({ }^{*} 1 \text { in }=2,54 \mathrm{~cm}\right) \\
& =25 \times 2,54 \\
& =63,5 \mathrm{~cm}=635 \mathrm{~mm} \sim \mathbf{6 5 0} \mathbf{~} \mathbf{~ m m}
\end{aligned}
$$$$
\text { 3. Panjang Besi }=25 \text { in }(\text { dari tabel } 3.21)\left({ }^{*} 1 \text { in }=2,54 \mathrm{~cm}\right)
$$

\subsection{Perhitungan Tebal Pelat Beton Dengan Metode AASHTO 1993}

1. Umur rencana $=20$ tahun

2. CBR tanah dasar : $5 \%$

3. Factor distribusi arah (Dd) $=$ diambil 0,5

4. Factor distribusi lajur (DL) $=100 \%$

5. $\mathrm{Fc}^{\prime}$ pelat beton $=350 \mathrm{~kg} / \mathrm{cm}^{2}=34,3 \mathrm{Mpa}=4978 \mathrm{Psi}$

6. Data lalu lintas harian rata - rata :

$$
\begin{array}{ll}
\text { Mobil penumpang } & =2919 \\
\text { Mobil Pick up, combi } & =900 \\
\text { Bus } & =90 \\
\text { Truck } 2 \text { as } 13 \text { ton } & =25
\end{array}
$$

7. pertumbuhan lalu lintas (i) $\quad=5 \%$ (ketentuan dari AASHTO 1993)

Direncanakan perkerasan kaku untuk 2/2 UD 2 lajur 2 arah tak terbagi untuk jalan kolektor

8. Terminal serviceability $(\mathrm{Pt})=2.0$

Nilai $\mathrm{Pt}=2.0$ untuk jalan kolektor

9. initial serviceability $(\mathrm{P} 0)=4.5$

(berdasarkan AASHTO 1993, nilai Po untuk perkerasan kaku adalah 4.5 )

10. serviceability loss, $\Delta \mathrm{PSI}=\mathrm{PO}-\mathrm{Pt}=4.5-2.0=2.5$

11. Reability, $\mathrm{R}=90 \%$

12. standard normal deviation, $\mathrm{ZR}=-1.282$

13. standard deviation, $($ So $)=0,35$

Berdasarkan AASHTO 1993 , nilai standard deviation (So) untuk perkerasan kaku antara $0,3-0,4$ maka diambil : 0,35

14. $\mathrm{MR}=7500$

Nilai CBR tanah dasar sebesar $=5 \%$ maka nilai MR bisa didapatkan dengan menggunakan rumus sebagai berikut

$\mathrm{MR}=1500 \times \mathrm{CBR}$

$\mathrm{MR}=1500 \times 5 \quad=7500$

15. $\mathrm{ESB}=500000 \mathrm{Psi}$

karena LMC merupakan campuran semen agregat ( cement aggregate mixtures)

16. perhitungan ESAL 
JTS : Jurnal Teknik

P-ISSN: 2302-8734

E-ISSN: 2581-0006

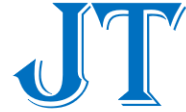

FT UMT
Vol. 9 No. 2 Th. 2020

Halaman : 34 - 43

November 2020

$W t=W 18 x \frac{(1+g)^{n}-1}{g}$

Dimana :

$\mathrm{Wt}=$ Jumlah beban gandar tunggal standar kumulatif

$\mathrm{W} 18=$ Beban gandar standard kumulatif selama 1 tahun

$\mathrm{n} \quad=$ umur pelayanan, atau umur rencana UR (tahun)

$\mathrm{g}=$ perkembangan lalu - lintas $(\%)$

\begin{tabular}{|c|l|c|c|c|c|c|c|}
\hline No & Jenis kendaraan & $\begin{array}{c}\text { Lalin } \\
\text { skrg }\end{array}$ & VDF & DD & DL \% & $\begin{array}{c}\text { hari } \\
\text { dalam } \\
\text { setahun }\end{array}$ & W18 \\
\hline 1 & 1 & 2 & 3 & 4 & 5 & 6 & 7 \\
\hline 2 & Mobil Penumpang & 2919 & 0,00012 & 0,5 & 1 & 365 & 63,9261 \\
\hline 3 & Mobil Pick up, combi & 900 & 0,2165 & 0,5 & 1 & 365 & 35560,125 \\
\hline 4 & Bus & 90 & 2,9918 & 0,5 & 1 & 365 & 49140,315 \\
\hline 5 & truck 2 as 13 ton & 25 & 0,2458 & 0,5 & 1 & 365 & 1121,4625 \\
\hline \multicolumn{7}{|c|}{ Total } \\
\hline
\end{tabular}

$$
\begin{aligned}
& W t=W 18 \times \frac{(1+g)^{n}-1}{g} \\
& ==80228,50 \times \frac{(1+5)^{20}-1}{5}=53,340,025
\end{aligned}
$$

Jadi didapat nilai lalu lintas kumulatif selama umur rencana $=53,340,025$

Tebal subbase yang digunakan adalah sebesar 6 inch $=152 \mathrm{~mm}$

Ditebtukan dengan menggunakkan diagram berikut :

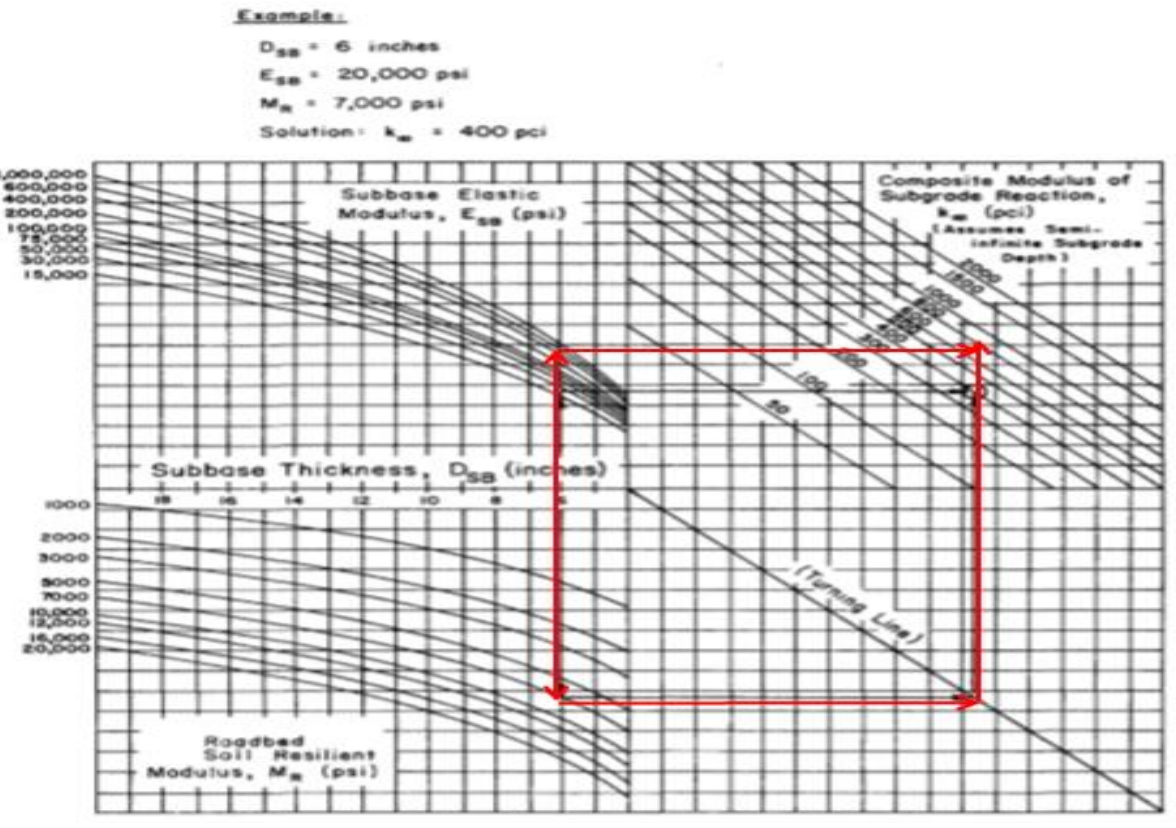

Diagram untuk menentukan modulus reaksi subgrade $(\mathrm{k})$

Berdasarkan diagram diatas maka didapat nilai $\mathrm{k}$ sebesar $=700 \mathrm{pci}$

16. Menentukan tebal slab berdasarkan metode AASHTO 1993 
JTS : Jurnal Teknik

P-ISSN: 2302-8734

E-ISSN: 2581-0006

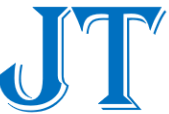

FT UMT
Vol. 9 No. 2 Th. 2020

Halaman : 34 - 43

November 2020

1. modulus elasitisitas beton $(\mathrm{EC})=$

$$
E C=57000 \sqrt{f c^{\prime}}
$$

$\mathrm{Fc}^{\prime}=350 \mathrm{~kg} / \mathrm{cm}^{2}=34,3 \mathrm{Mpa}=4978 \mathrm{psi}$

$$
E C=57000 \sqrt{4978}
$$

$\mathrm{EC}=4021631,758 \mathrm{psi}=4 \mathrm{E}+06 \mathrm{psi}$

2. menentukan modulus of repture $(\mathrm{Sc})$

$\mathrm{Sc}=650 \mathrm{psi}=4,48 \mathrm{Mpa}=45,7 \mathrm{~kg} / \mathrm{cm}^{2}$

3. Drainage coefficient $(\mathrm{Cd})=$

Berdasarkan tabel AASHTO 1993 untuk perkerasan kaku nilai $\mathrm{Cd}=1$ 1,2. menentukan Load Transfer Coefficient (J). Berdasarkan AASHTO 1993 untuk perkerasan kaku tipe peerkerasan beton semen dengan tulangan sambungan maka nilai $\mathrm{J}=2,5$.

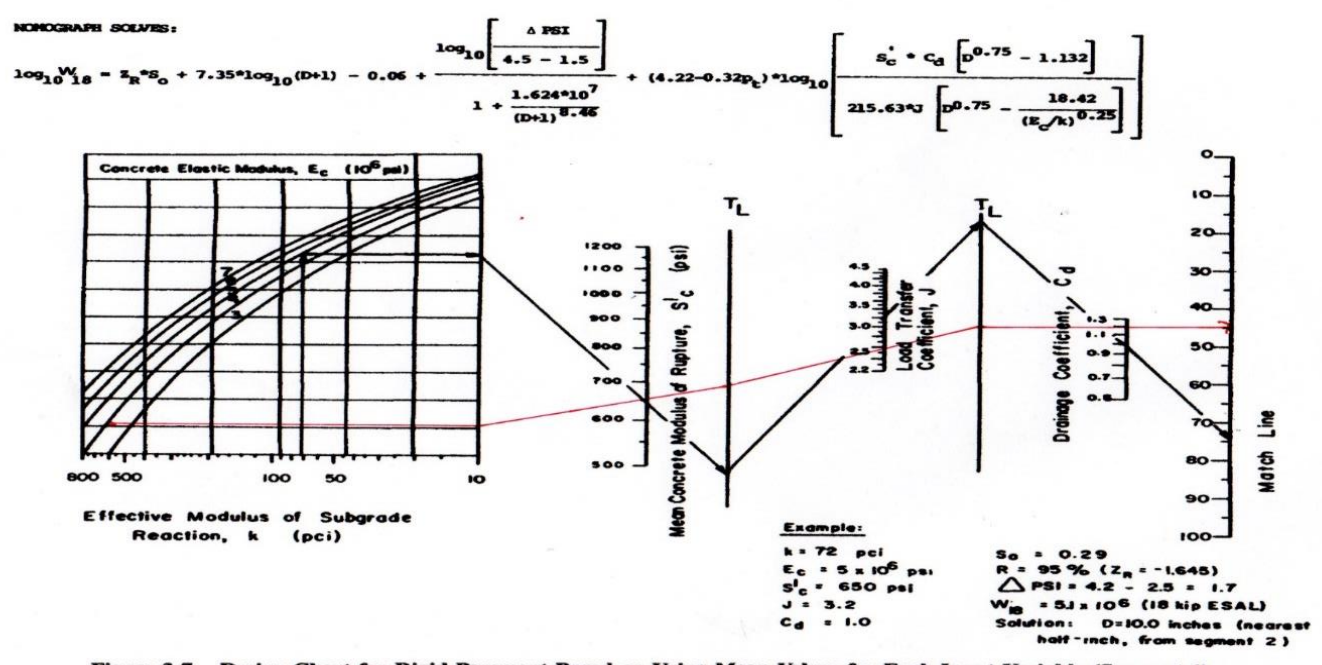

Figure 3.7. Design Chart for Rigid Pavement Based on Using Mean Values for Each Input Variable (Segment 1) -

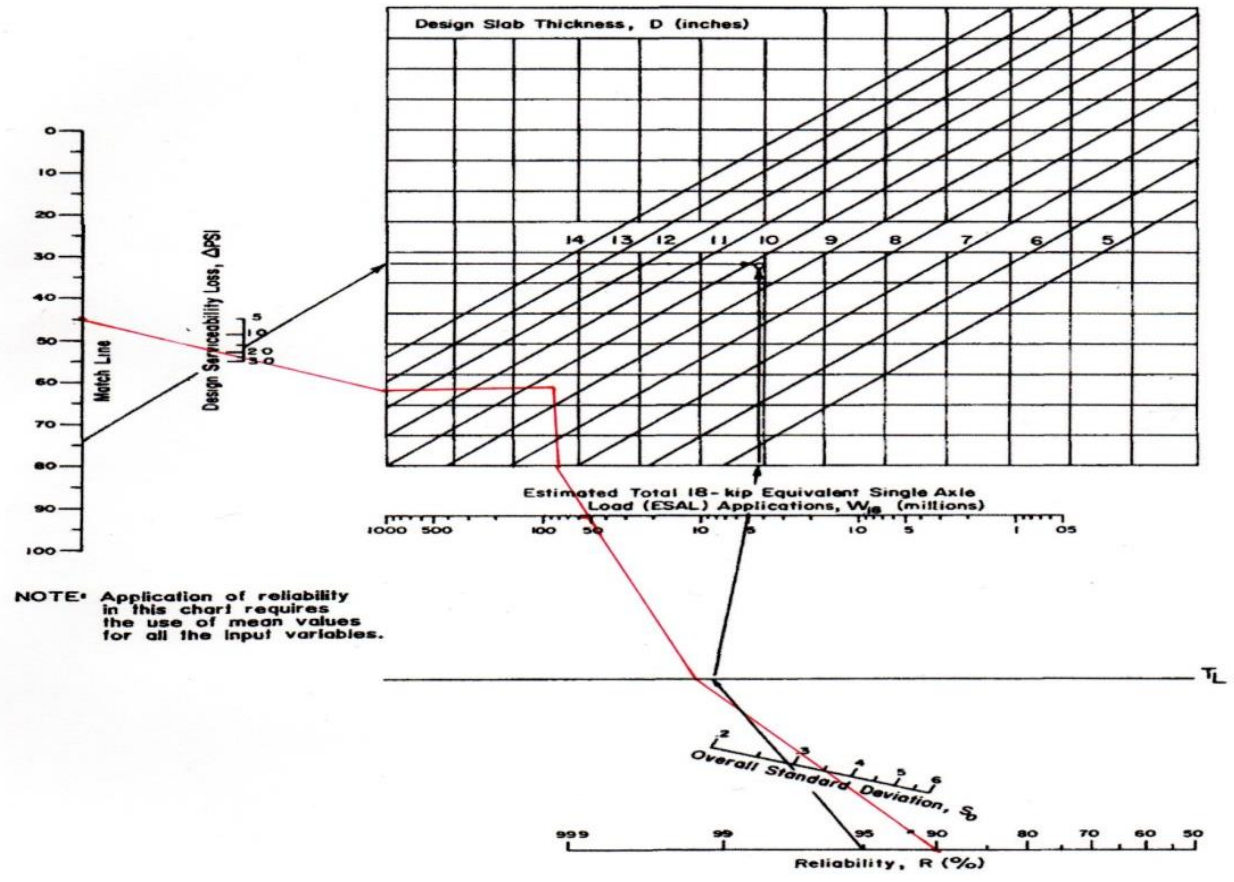

http://jurnal.umt.ac.id/index.php/it/index 
Berdasarkan metode yang dgunakan pada perhitungan diatas, didapatkan hasil tebal pelat beton $267 \mathrm{~mm}$. dengan menggunakan lapis pondasi LMC (Lean Mix Concrete) adalah $10 \mathrm{~cm}$ dan juga lapis pondasi agregat kelas $\mathrm{A}=15 \mathrm{~cm}$. dengan sambungan dowel : 32 dengan panjang 450 sejarak $300 \mathrm{~mm}$ dengan sambungan tiebar : 13 dengan panjang 635 sejarak $813 \mathrm{~mm}$.

\section{Kesimpulan}

\section{KESIMPULAN DAN SARAN}

1. Pada perencanaan tebal perkerasan kaku metode bina marga 2017 dengan CBR desain 5\% dihasilkan umur rencana selama 40 tahun dengan lapis pondasi LMC $=10 \mathrm{~cm}$, lapis pondasi agregat kelas $\mathrm{A}=12 \mathrm{~cm}$ dan tebal beton $=22 \mathrm{~cm}$

2. Pada perencanaan tebal perkerasan kaku metode AASHTO 1993 dengan CBR desain 5\% dihasilkan umur rencana 20 tahun, dengan reability $90 \%$, kmodulus tanah dasar $=700$ pci menggunakan subbase $L M C=10 \mathrm{~cm}$, pondasi agregat kelas $\mathrm{A}=15 \mathrm{~cm}$ dan tebal beton $=26 \mathrm{~cm}$

3. Perbandingan perencanaan metode bina marga dan AASHTO 1993

\begin{tabular}{|l|l|l|}
\hline NO & \multicolumn{1}{|c|}{ Metode Bina Marga 2017 } & \multicolumn{1}{c|}{ Metode AASHTO 1993 } \\
\hline 1 & Umur rencana 40 tahun & Umur rencana 20 tahun \\
\hline 2 & $\begin{array}{l}\text { Pada perhitungan CBR tanah, data } \\
\text { yang diperoleh hasil perhitungan } \\
\text { CBR dapat langsung digunakan } \\
\text { pada perencanaan. }\end{array}$ & $\begin{array}{l}\text { Pada perhitungan CBR tanah, data yang } \\
\text { diperoleh hasil dari perhitungan CBR } \\
\text { dipakai lagi untuk menghitung modulus } \\
\text { reaksi tanah dasar (k) terlebih dahulu }\end{array}$ \\
\hline 3 & $\begin{array}{l}\text { Perhitungan pada metode ini jauh } \\
\text { lebih sedikit dibandingkan } \\
\text { AASHTO 1993 dikarenakan tidak } \\
\text { ada menentukan parameter } \\
\text { Reliability (R), Standar Normal } \\
\text { Deviasi (ZR), Standar Deviasi (So), } \\
\text { dan parameter Serviceability seperti } \\
\text { (pt) dan (po) }\end{array}$ & $\begin{array}{l}\text { Sedangkan pada metode ini perhitungan } \\
\text { lebih banyak dari Bina Marga yaitu ada } \\
\text { menentukan nilai parameter Reliability } \\
\text { (R), Standar Normal Deviasi (ZR), } \\
\text { Standar Deviasi (So), dan parameter } \\
\text { Serviceability seperti (pt) dan (po) }\end{array}$ \\
\hline 4 & $\begin{array}{l}\text { Tebal perkerasan yang diperoleh } \\
\text { yaitu 22 cm yang lebih tipis } \\
\text { dibandingkan AASHTO 1993 yaitu } \\
\text { 26 cm, sehingga dari segi biaya } \\
\text { metode ini lebih ekonomis } \\
\text { dibandingkan metode AASHTO } \\
\text { 1993 jika mutu beton yang } \\
\text { digunakan sama yaitu K-350 }\end{array}$ & $\begin{array}{l}\text { Tebal perkerasan yang diperoleh yaitu } \\
\text { 26 cm yang lebih tebal dibandingkan } \\
\text { Bina Marga 2017 yaitu 22 cm, sehingga } \\
\text { dari segi biaya metode ini lebih mahal } \\
\text { dibandingkan metode bina marga 2017 } \\
\text { jika digunakan mutu beton yang sama } \\
\text { yaitu K-350. }\end{array}$ \\
\hline
\end{tabular}

\section{Saran}

Untuk perencanaan AASHTO 1993 dalam penentuan tebal pelat perlu ketelitian yang tinggi untuk mendapatkan ketebalan yang sesuai

\section{DAFTAR PUSTAKA}

AASHTO. 1993, Guide for The Design of Pavement Structures. Washington DC. 
JTS : Jurnal Teknik

Ari Suryawan, 2015, Perkerasan Jalan Beton Semen Portland (Rigid Pavement), Yogyakarta, Penerbit Beta Offset Yogyakarta

Hamirhan Saodang, 2010 Kontruksi Jalan Raya, Bandung, Penerbit Nova Kementrian Pekerjaan Umun Dan Perumahan Rakyat Direktorat Jendral Bina Marga. (2017), Manual Perkerasan Jalan Nomor 04/SE/Db/2017. Pd T-14-2003.

Metode bina marga 2003 Perencanan tebal lapis perkerasan kaku (studi kasus: Jalan akses tol cilegon barat )

Wely pradita Bin Maryulis 2011, Perencanaan Perkerasan Jalan Beton Semen.

Umam, Bethary, 2016, Tata Cara Perencanaan Geometri 